\title{
Massive heterotopic ossification associated with late deficits in posterior wall of acetabulum after failed acetabular fracture operation
}

\author{
Yuntong Zhang, Yang Xie*, Shuogui Xu ${ }^{*}$ and Chuncai Zhang
}

\begin{abstract}
Background: Heterotopic ossification is a common postoperative complication of acetabular fracture. However, functionally significant heterotopic ossification with associated late bone defects in the posterior wall of the acetabulum is rare and challenging to treat. When heterotopic ossification is a late complication of failed acetabular fracture operation, it is disabling and may only be treated by THA. THA is highly susceptible to premature failure in young and active patients and may require numerous revisions.
\end{abstract}

Case presentation: This article describes a 40-year-old man with massive heterotopic ossification associated with late bone defects in the posterior wall of the acetabulum after a failed acetabular fracture operation. The primary fracture type was a 62-A2.3 fracture according to the AO/OTA Classification.Surgical excision and anatomical reconstruction of the acetabular wall using heterotopic ossific bone were performed 10 months after the fracture repair. Postoperatively, indomethacin was administered for prophylaxis against recurrence of heterotopic ossification, and hip range of motion was progressively increased. At 5 years and 6 months follow-up, the patient's pain was relieved and hip function had recovered. Though radiography and CT showed minimal subchondral cysts and mild joint-space narrowing, there was no evidence of graft resorption, progressive posttraumatic osteoarthritis or necrosis of the femoral head.

Conclusion: To the authors' knowledge, this is the first case of such a challenging condition. Although it is an extremely rare case, it provides an attractive option for avoiding THA, as the long-term follow-up shows a satisfactory outcome.

Keywords: Heterotopic ossification, Late bone defects, Posterior wall, Acetabulum, Acetabular fracture

\section{Background}

Heterotopic ossification ( $\mathrm{HO})$, the development of bone outside its normal location in the skeleton, is a common postoperative complication of acetabular fractures [1]. Irradiation and indomethacin have been shown to be effective in the prevention of severe heterotopic ossification [2]. However, once formed, heterotopic bone can be managed only with surgical excision [3]. In one study, functionally significant heterotopic ossification (Brooker et al. class III or IV) developed in $23 \%$ of those patients who did not receive regular prophylaxis [1]. Although surgical excision of heterotopic ossification has been

\footnotetext{
* Correspondence: 106694832@qq.com; zone1030@gmail.com

Department of orthopaedics, Changhai Hospital, Second Military Medical University, Shanghai 200433, China
}

reported with satisfactory results $[4,5]$, the management of disabling $\mathrm{HO}$ with associated bone defects in the posterior wall of the acetabulum is a challenge for surgeons and has not been reported to the best of our knowledge.

We describe a rare case of massive $\mathrm{HO}$ surrounding the hip joint with associated bone defects in the posterior wall of the acetabulum following a failed operation of acetabular fractures. The management and outcome, five years and six months after the excision, as well as measures to prevent recurrence are discussed. Informed consent for participation in the study was obtained from the patient.

\section{Case presentation}

A forty-year-old man presented with a posterior column fracture of the acetabulum and ipsilateral inferior ramus

\section{() Biomed Central}


of the pubis fracture associated with enterorrhexis of the rectum due to a traffic accident on Mar. $25^{\text {th }}, 2006$. Emergency repair of the rectum was performed immediately after the injury. During emergency exploration and repair, the pelvic fracture was determined to have no relation to the rectal injury, thus defining the fracture as a closed fracture. The primary acetabular fracture was a 62-A2.3 fracture according to the AO/OTA Classification. After eleven days in stabilized condition, the patient accepted an open reduction and internal fixation surgery through a posterolateral approach in a local hospital. However, the fracture was not reduced after the first surgery. The postoperative radiographic images (Figure 1) show that two lock reconstruction plates were planted, but the displaced posterior column fracture was not restored anatomically, and the comminuted posterior wall fracture was not fixed rigidly. On Jan.10 ${ }^{\text {th }}, 2007$, the patient presented to our outpatient clinic with increasing hip pain with weight-bearing and severe claudication. On physical examination, the affected limb was $3 \mathrm{~cm}$ shortened. Range of motion of the hip was limited to $20^{\circ}$ in flexion, $0^{\circ}$ in extension, $15^{\circ}$ in adduction, and $0^{\circ}$ in abduction. The radiographic images (Figures 2, 3, 4 and 5), including CT scans and three-dimensional reconstruction, revealed posterior subluxation and mal-union of the posterior column fracture, nonunion and bone defects in the posterior wall, and old impaction and degeneration at the posteroinferior portion of femoral head. Moreover, a massive osseous lesion existed in the posterolateral aspect of acetabulum, partially connected to

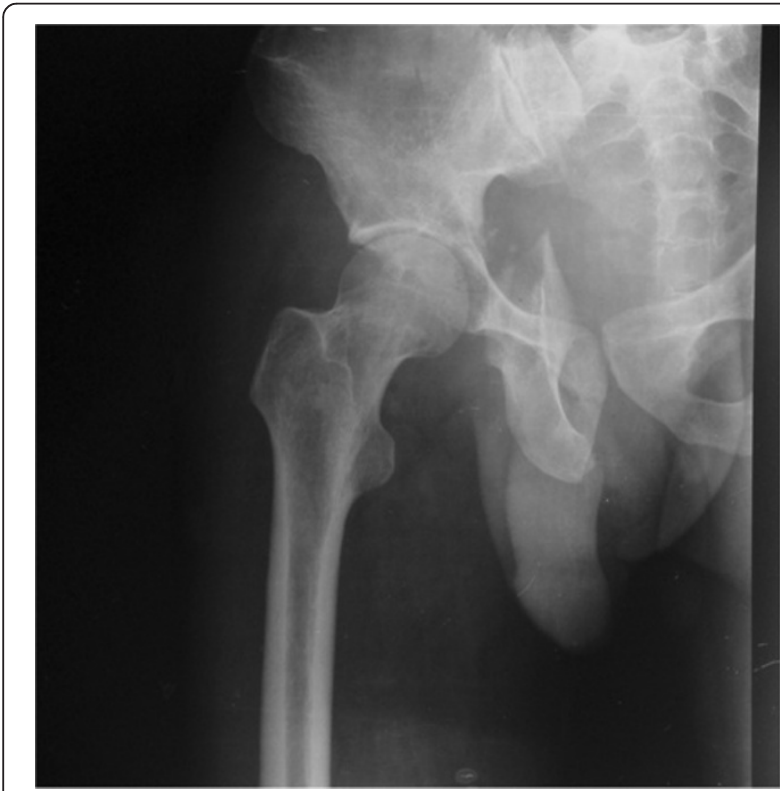

Figure 1 An AP view of the right hip after injury shows a posterior wall and column fracture of the right acetabulum and a fracture of the ipsilateral inferior ramus of pubis.

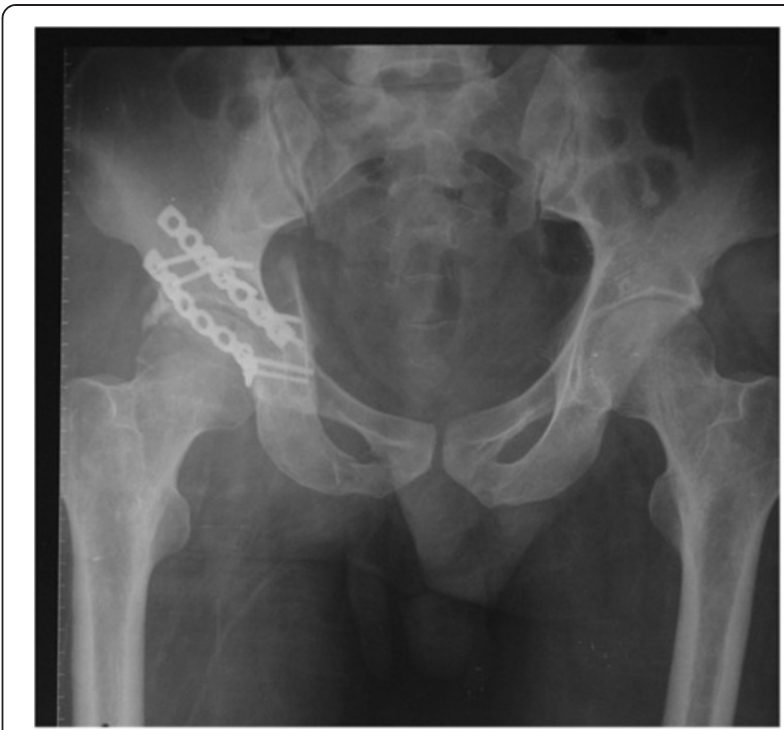

Figure 2 An AP view of the pelvis after initial operation shows that two lock reconstruction plates were planted, but the displaced posterior column fracture was not restored anatomically and the comminuted posterior wall fracture was not fixed rigidly.

the posterior column and surrounding the whole posterosuperior hip joint from the roof of the acetabulum to the intertrochanteric line. The osteoarthritic changes, including joint space narrowing, osteophyte formation, and subchondral lesions, were observed in the posterior area of the hip joint. However, more than $50 \%$ of the joint space remained, and the $\mathrm{CT}$ scan and three-

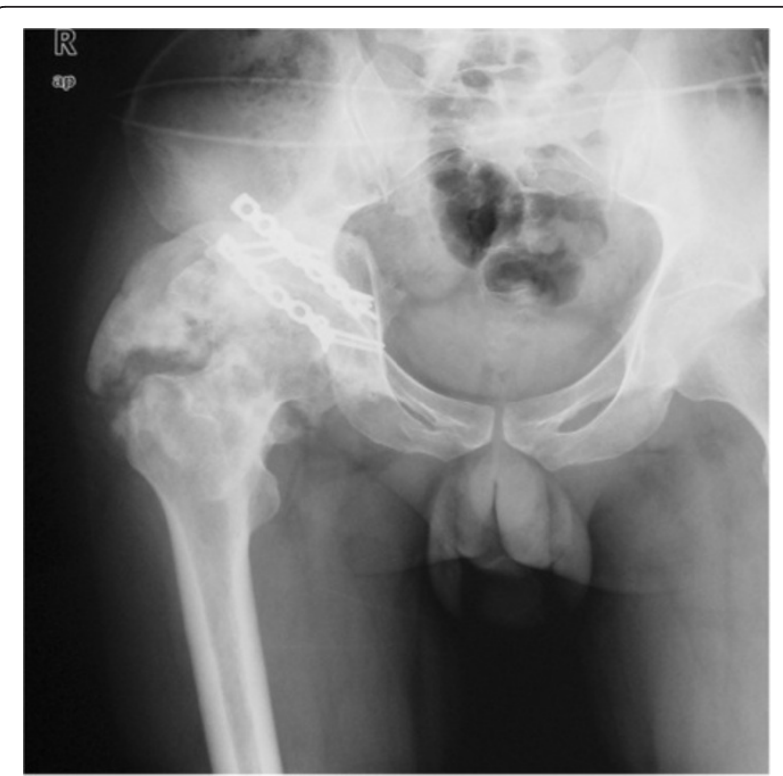

Figure 3 An AP view of the pelvis after 10 months shows a massive osseous lesion in the posterolateral aspect of the acetabulum. 


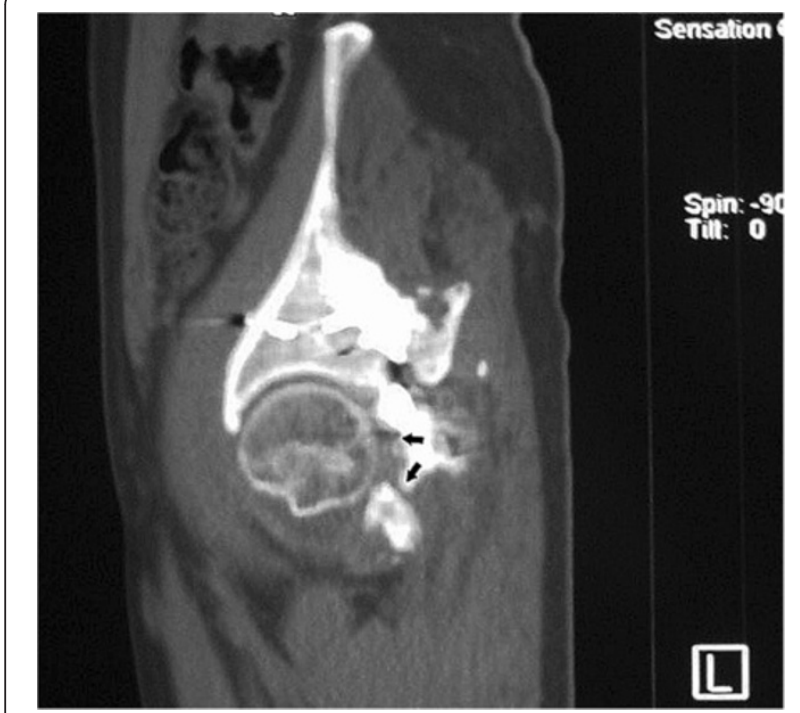

Figure 4 Coronal CT scan shows incongruent reduction of the hip joint and mal-union in the posterior wall and column of the acetabulum (arrows). However, more than 50\% of joint space was maintained and no evidence of collapse or necrosis in femoral head was revealed.

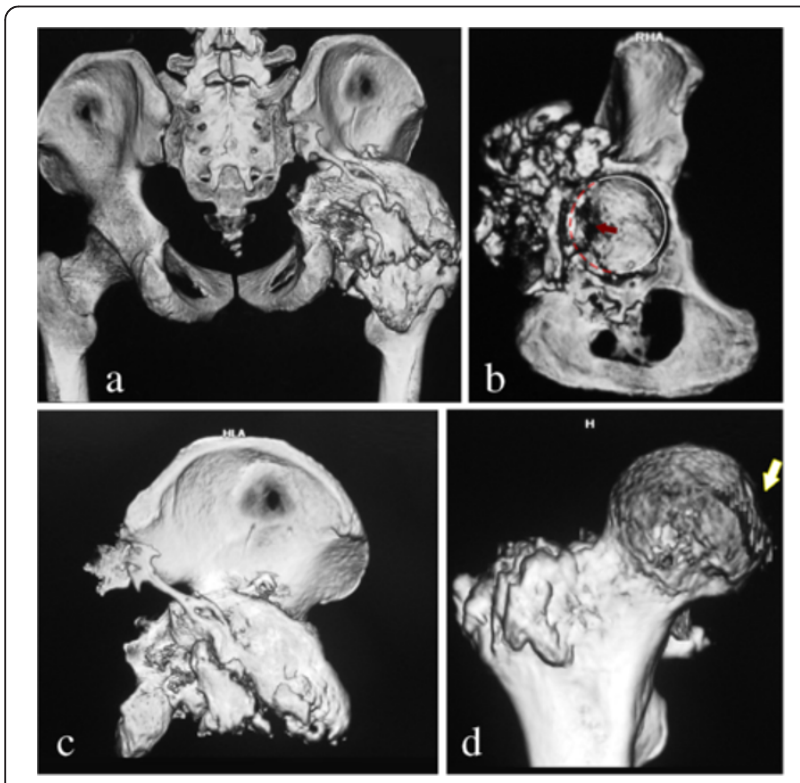

Figure $\mathbf{5}$ Three-dimensional CT reconstruction. (a) The massive osseous lesion in the posterolateral aspect of the acetabulum, partially connected with the posterior column, and surrounding the whole posterior hip joint from the roof of the acetabulum to the intertrochanteric line. $(\mathbf{b}, \mathbf{c})$ Bone defects and joint incongruence were revealed in the posterior wall (red dotted line and arrow in $\mathbf{b}$ ). (d) Old impaction and degeneration exist at the posteroinferior portion of femoral head (white arrow in d). However, the weightbearing portion of the femoral head had a normal appearance. dimensional reconstruction showed no evidence of collapse or necrosis. According to the medical record, no related therapy, including pharmacological or localized irradiation, was used for the prevention of heterotopic ossification.

To establish the diagnosis and relieve symptoms, the patient underwent operative excision of the osseous lesion in the hip and anatomical reconstruction of the posterior acetabular wall using structured iliac crest autograft with a Kocher-Langenbeck approach 9 months after the primary injury. The greater trochanter osteotomy was used to allow better access to the superior acetabulum. The large osseous lesion (Figure 6a) adhering to the surrounding tissue and bone was removed en bloc after meticulous release (Figure 6b). The total weight of heterotopic ossific bone excised was approximately $515 \mathrm{~g}$ (Figure 6c). The screws and plates from the former operation were removed. The sciatic nerve was identified and carefully preserved during the approach and release. A large defect was noticed after removal of the bony mass (Figure 7), and the joints were unstable on examination. The posterior acetabular wall defect was reconstructed with structured autograft (Figure 8) harvested from the largest heterotopic ossific bone using an appropriate-sized acetabular reamer. The size of acetabular reamer was determined by the diameter of the femoral head and the depth of the acetabular fossa measured by radiography. The graft was then placed in the acetabular wall defect and fixed temporarily with two K-wires. A new method called acetabular tridimensional memory alloy

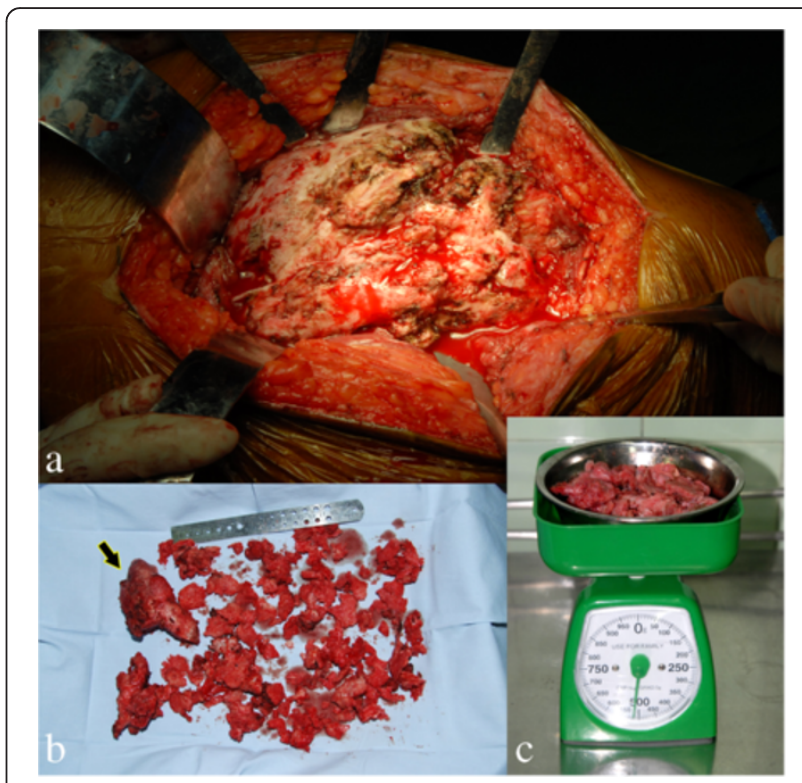

Figure 6 Intra-operative photograph. (a) The large osseous lesionadhering to the surrounding tissue and (b) bone was removed en bloc after meticulous release. (c) The total weight of heterotopic ossific bone excised was about $515 \mathrm{~g}$. 


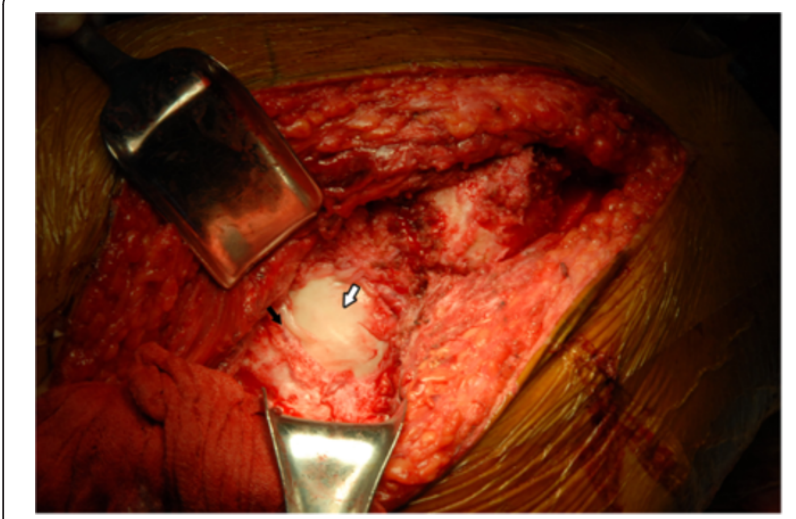

Figure 7 An intraoperative picture shows a large defect (black arrow) in the posterior wall of the acetabulum. The white arrow indicates the femoral head.

fixation system (ATMFS), which has been satisfactorily used for treatment of posterior wall fractures of the acetabulum, was used for internal fixation [6-8]. The procedure of planting ATMFS was exactly the same as described in the related literature [6,7]. The two K-wires were then removed, and the wound was washed and closed around a drainage tube.

The drainage tube was removed 2 days after surgery. In the postoperative period, prophylaxis for recurrence of heterotopic ossification (indomethacin $25 \mathrm{mg}$ three times daily) was administered for 6 weeks. Isometric contraction training of the lower limbs was encouraged starting one day after surgery. One week after surgery, the patient was asked to initiate and gradually increase the degree of extension and flexion of the hip while supine. Partial, toe-touch weight bearing with crutches or a walker was allowed four weeks postoperatively. Complete weight bearing on the affected limb was restricted until radiography demonstrated signs of union.

At the final follow-up examination 5 years and 6 months after the reconstructive surgery, the pain was relieved, the patient could walk by himself, the function of the injured joint was similar to the normal side (Figure 9), and the range of motion of the hip was improved, with flexion improved to $120^{\circ}$, extension to $5^{\circ}$, adduction to $30^{\circ}$ and abduction to $15^{\circ}$. Radiographs of the hip (Figures 10 and 11) showed slight recurrence of the ossified mass (Brooker et al. class II, mature), but with a certain distance to the joint. In addition, more than $50 \%$ of the joint space was maintained, and the femoral head was mostly congruent with the acetabulum. Although subchondral cysts and minimal signs of arthritis could be observed in the femoral head and acetabulum, no evidence of collapse or necrosis was found either in femoral or acetabular subchondral bone. The modified Merle d'Aubigne and Postel's clinical outcome evaluation was scored as excellent. The Matta's radiographic evaluation was scored as good.

The authors clarify that the written informed consent for participation and publication of clinical images was obtained from the patient in our study.

\section{Conclusion}

The etiopathogenesis of $\mathrm{HO}$, though incompletely understood, involves genetic abnormalities, neurologic injury, and musculoskeletal trauma [9]. The high incidence of
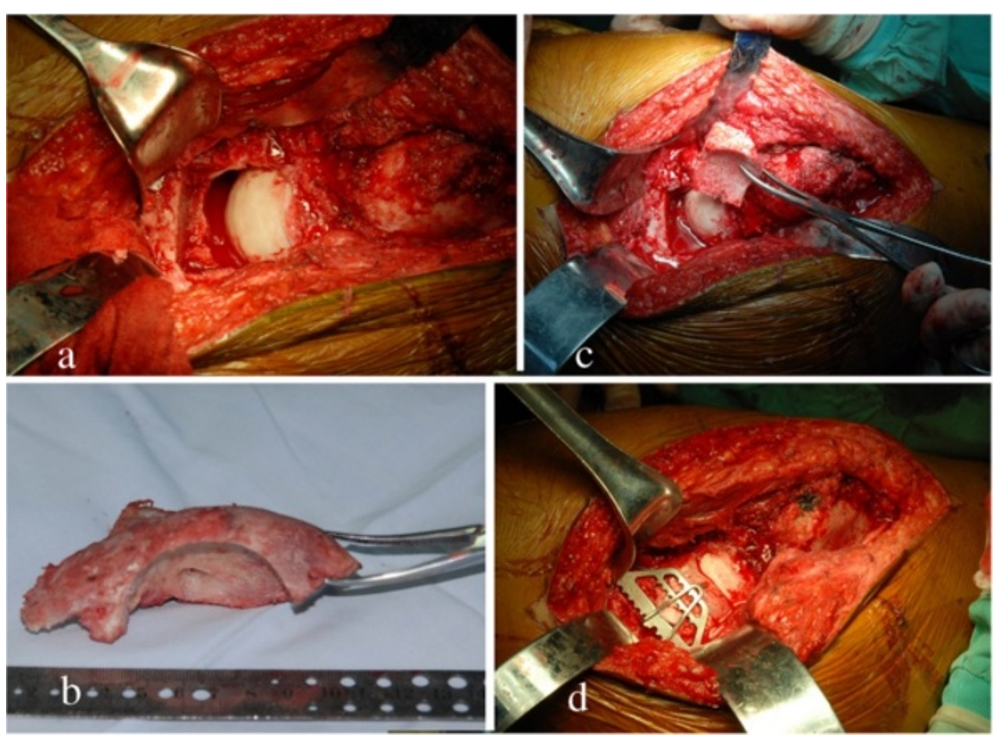

Figure 8 Intra-operative photograph. $(\mathbf{a}, \mathbf{b})$ The posterior acetabular wall defect was reconstructed with structured autograft harvested from the largest heterotopic ossific bone using an appropriate-sized acetabular reamer. (c) Then, the graft was placed in the deficiency. (d) Acetabular tridimensional memory alloy fixation system was used for internal fixation. 


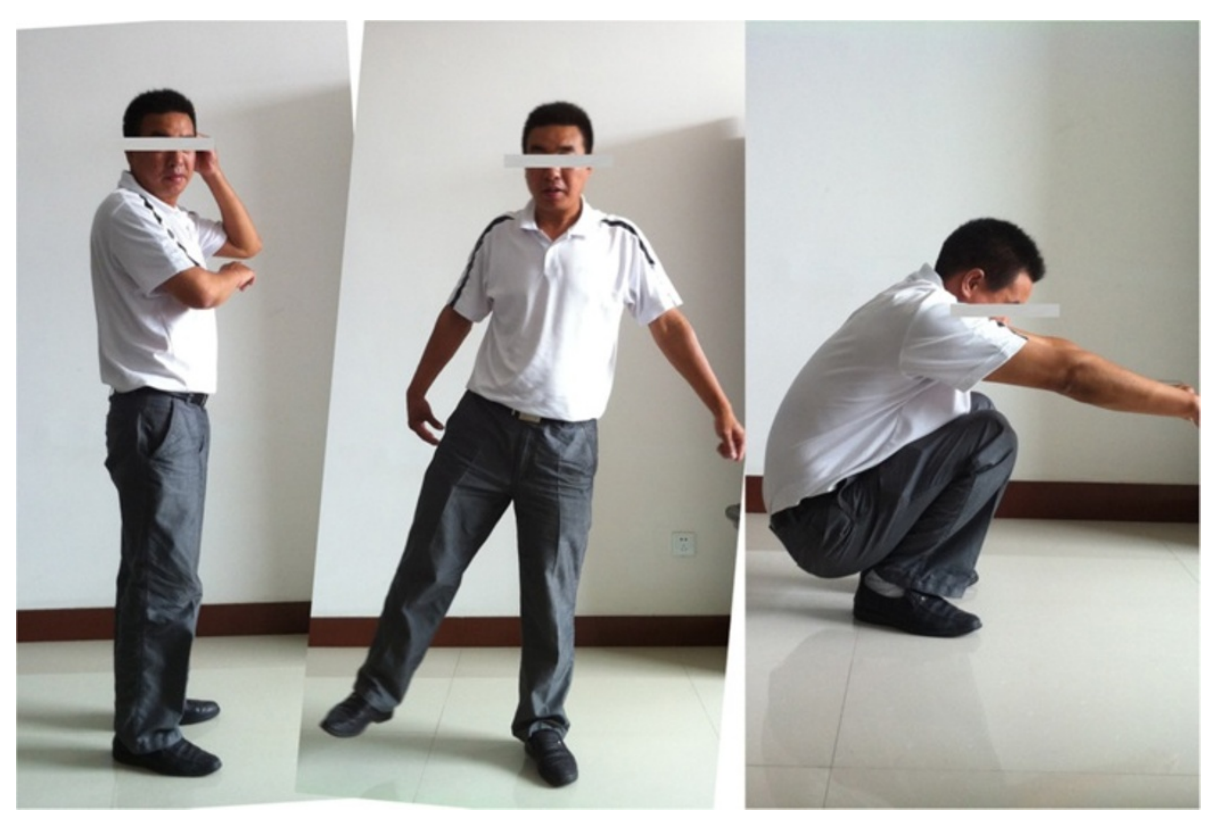

Figure 9 At the final follow-up examination 5 years and 6 months after the reconstructive surgery, the patient could walk by himself and the function of the injured joint was similar to the normal side.
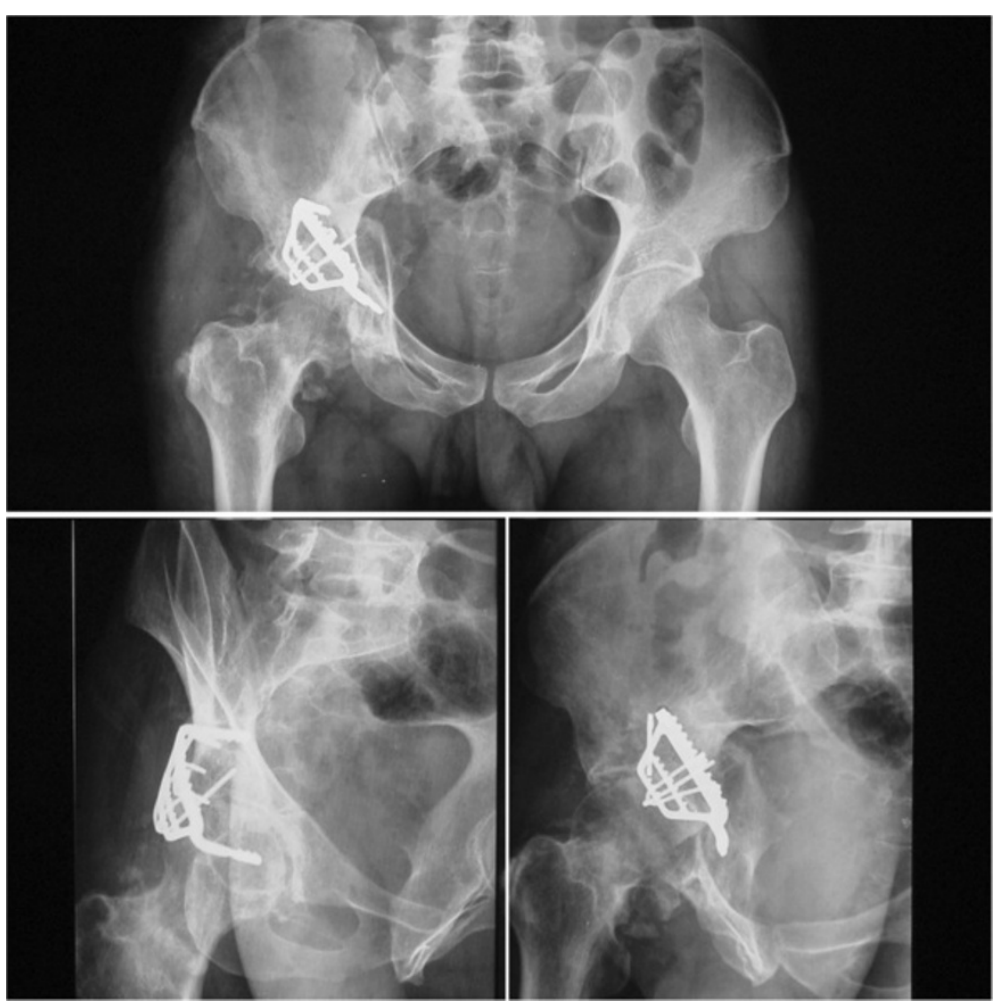

Figure $10 \mathrm{AP}$ view and Judet oblique views obtained 5 years and 6 months postoperatively show slight recurrence of the ossified mass. 


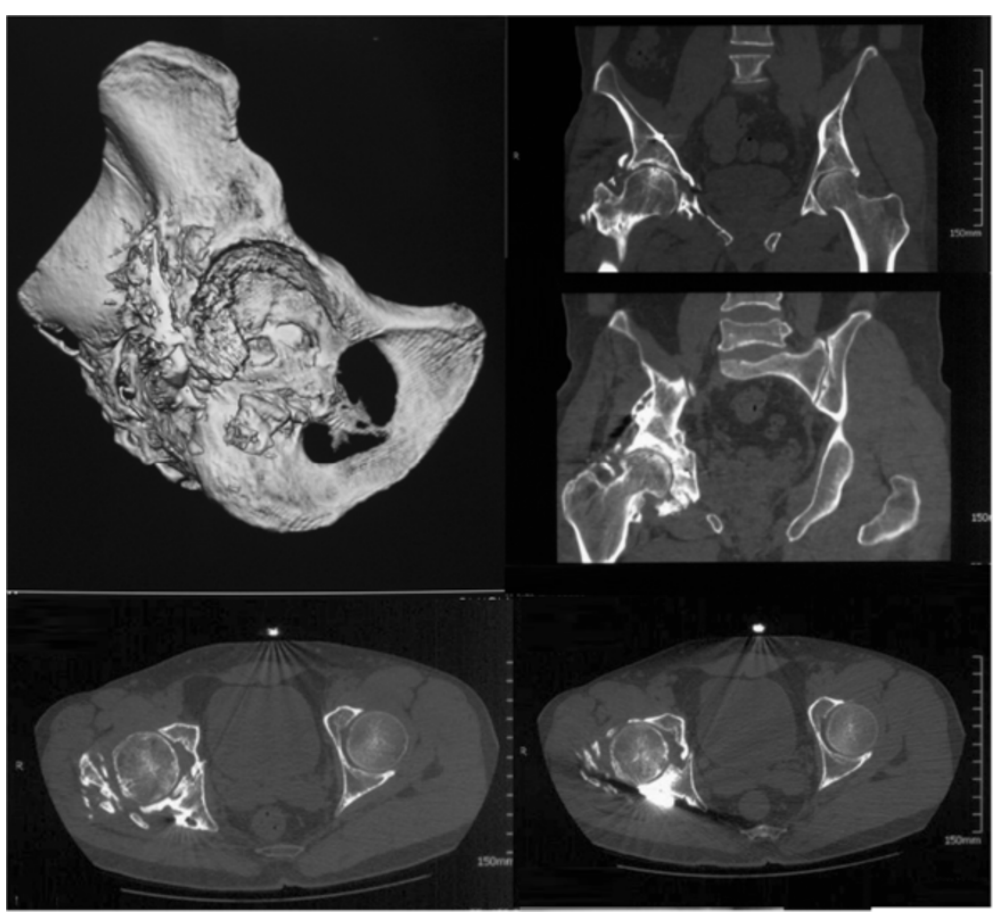

Figure $11 \mathrm{CT}$ scans and reconstruction at the final follow-up show more than $50 \%$ of joint space existed and the femoral head was mostly congruent with the acetabulum. Although subchondral cysts and minimal signs of arthritis can be observed in the femoral head and acetabulum, no evidence of collapse or necrosis was found either in the femoral or acetabular subchondral bone.

radiographic $\mathrm{HO}$ and potential morbidity after acetabular surgery has led to the standardization of prophylactic therapies [10-13]. Irradiation and indomethacin are thought to be effective in the prevention of heterotopic ossification. According to recent studies, both indomethacin and radiation therapy variably decrease the rates of severe $\mathrm{HO}$ after acetabular surgery by $4 \%$ to $15 \%[14,15]$. However, other studies have not verified this reduction. Sean M. et al. [16] found no reduction in HO rates after acetabular surgery with indomethacin compared with placebo.

The patient in our study did not accept any prophylaxis after the first surgery, which we conclude was the main cause of such massive heterotopic ossification. Therefore, indomethacin ( $25 \mathrm{mg}$ three times daily) was administered for 6 weeks in the postoperative period as prophylaxis for recurrence of heterotopic ossification. Radiation therapy was not applied due to poor compliance, poor tolerance, and radiation-associated morbidities. In cases of mature hyperostotic macrodactyly, operative resection of the deposits or the osteophytes might be indicated when pain increases or the range of motion is limited.

A literature review revealed reports of satisfactory results from surgical resection of $\mathrm{HO}$ followed by indomethacin therapy after failed open reduction and internal fixation or total hip arthroplasty. Wick et al. [4] retrospectively analyzed the clinical effect of surgical excision of heterotopic bone after hip surgery in 21 patients. Of these patients, 19 (90.4\%) had excellent relief of pain and improved hip range of motion. Only one patient $(4.8 \%)$ suffered a recurrence of heterotopic bone formation. Cobb et al. [5] evaluated the outcomes of excision of heterotopic ossification after total hip arthroplasty. In all 53 cases, joint function was significantly improved. However, disabling $\mathrm{HO}$ with associated bone defects, mal-union in the posterior wall and incongruence of the hip joint following a failed operation of acetabular fractures have not been previously reported. Bone defect in the posterior wall of the acetabulum and joint incongruence can significantly affect the stability of the hip and lead to high incidence of posttraumatic arthritis [17]. Thus, merely the resection of the HO can hardly contribute to a favorable outcome. The usual treatment method described in the literature includes two options: one therapeutic alternative is THA $[18,19]$. However, posterior acetabular wall fractures occur predominantly in individuals younger than 40 years old. These exceptionally active patients are highly susceptible to premature failure of arthroplasty and may require numerous revisions throughout their lives. Another option is reconstruction of the posterior wall with the use of a graft. Among the various graft materials, the iliac crest autograft 
is the most common and reliable measure [20]. Nevertheless, only a few reports described reconstruction of posterior wall deficits of the acetabulum using iliac crest autograft. Daum et al. [21] first described the method in two cases of acute comminuted posterior wall acetabular fractures in 1993. The long-term functional outcome was satisfactory in one case, whereas the other case needed total hip arthroplasty after two years. Sen et al. [20] reported a series of eight cases of similar fractures where the comminuted fragments were excised and the defect in the posterior acetabular wall was reconstructed with iliac crest strut graft. The medium-term clinical outcomes were satisfactory. To our knowledge, Zha et al. [22] uniquely performed the procedure for the treatment of late posterior acetabular wall deficits following unsuccessfully managed posterior wall fractures and recommended this procedure as a noteworthy technique, especially for pediatric patients or adults without posttraumatic osteoarthritis. Compared with their reports, our technique is unique because the autograft was structured by a reamer, which has exactly the same cambered surface as the posterior acetabular surface. Furthermore, the autograft was harvested from a large heterotopic ossific bone. In addition, a Ni-Ti shapedmemory alloy device named ATMFS was used for fixation instead of screws and plates. The fixation system, as a functional metal material, has been successfully used in acetabular fractures for many years [6].

At the final follow-up, though the radiography and CT showed minimal subchondral cysts and mild joint-space narrowing, there was no evidence of graft resorption, progressive posttraumatic osteoarthritis or necrosis of the femoral head. The patient's hip function had recovered well. We believe that the reconstruction in the presence of a concentrically reduced hip contributed to the favorable outcome. It is possible that with extension of the follow-up period, posttraumatic osteoarthritis of the hip would develop and progress, ultimately requiring THA. However, the surgical reconstruction significantly delayed the eventual THA, and the sufficient bone stock for seating of the prosthetic socket can be provided by the grafting procedure.

We report the first case of massive heterotopic ossification with associated posterior acetabular wall deficits. We also describe an audacious and unique treatment for anatomical reconstruction using heterotopic ossific bone. Although it is an extremely rare case, the longterm follow-up shows a satisfactory outcome, and it provides an attractive option for avoiding THA.

\section{Consent}

Written informed consent was obtained from the patient for publication of this Case report and any accompanying images. A copy of the written consent is available for review by the Editor of this journal.

\section{Competing interest}

The authors declare that they have no competing interests.

\section{Authors' contributions}

$Y Z$ and $C Z$ contributed to the study concepts, literature research and manuscript preparation. CZ is the guarantor of integrity of the entire study and participated in the operation and manuscript review. YX and SX participated in literature research, data acquisition and data analysis. All authors read and approved the final manuscript.

Received: 27 February 2013 Accepted: 17 December 2013 Published: 26 December 2013

\section{References}

1. Daum WJ, Scarborough MT, Gordon W, et al: Heterotopic ossification and other perioperative complications of acetabular fractures. J Orthop Traumatol 1992, 6:427-432.

2. Burd TA, Lowry KJ, Anglen JO: Indomethacin compared with localized irradiation for the prevention of heterotopic ossification following surgical treatment of acetabular fractures. J Bone Joint Surg Am 2001, 83-A:1783-1788.

3. Cohn RM, Schwarzkopf $R$, Jaffe F: Heterotopic ossification after total hip arthroplasty (THA). Am J Orthop 2011, 40:E232-E235.

4. Wick M, Müller EJ, Hahn MP, et al: Surgical excision of heterotopic bone after hip surgery followed by oral indomethacin application: is there a clinical benefit for the patient? Arch Orthop Trauma Surg 1999, 119:151-155.

5. Cobb TK, Berry DJ, Wallrichs SL, et al: Functional outcome of excision of heterotopic ossification after total hip arthroplasty. Clin Orthop Relat Res 1999, 361:131-139.

6. Liu XW, Xu SG, Zhang CC, Su JC: Application of a shape-memory alloy internal fixator for treatment of acetabular fractures with a follow-up of two to nine years in China. Int Orthop 2009, 34:1033-1041.

7. Zhang CC, Xu SG, Wang $\mathrm{L}$, et al: Design and clinical applications of acetabular tridimensional memory alloy-fixation system. Chin J Orthop 2002, 22:709-713.

8. Liu XW, Xu SG, Zhang CC, et al: Biomechanical study of posterior wall acetabular fracture fixation using acetabular tridimensional memory alloy-fixation system. Clini Biomech 2010, 25:312-317.

9. Sumner DR, Turner TM, Igloria $R$, et al: Functional adaptation and ingrowth of bone vary as a function of hip implant stiffness. J Biomech 1998, 31:909-917.

10. Nauth A: Heterotopic ossification in orthopaedic trauma. J Orthop Trauma 2012, 26:684-688.

11. MacFarlane RJ, Ng BH, Gamie Z, et al: Pharmacological treatment of heterotopic ossification following hip and acetabular surgery. Expert Opin Pharmacother 2008, 9:767-786.

12. Zeckey C, Hildebrand F, Frink M, Krettek C: Heterotopic ossification following implant surgery - epidemiology, therapeutical approaches, and current concepts. Semin Immunopathol 2011, 33:273-286.

13. Baird EO, Kang QK: Prophylaxis of heterotopic ossification - an updated review. J Orthop Surg Res 2009, 4:12.

14. Blokhuis TJ, Frölke JP: Is radiation superior to indomethacin to prevent heterotopic ossification in acetabular fractures? A systematic review. Clin Orthop Relat Res 2009, 467:526-530.

15. Karunakar MA, Sen A, Bosse MJ, Sims SH, Goulet JA, Kellam JF: Indomethacin as prophylaxis for heterotopic ossification after the operative treatment of fractures of the acetabulum. J Bone Joint Surg $\mathrm{Br}$ 2006, 88:1613-1617.

16. Sean MG, Stephen HS, Madhav AK, et al: Heterotopic Ossification Rates After Acetabular Fracture Surgery Are Unchanged Without Indomethacin Prophylaxis. Clin Orthop Relat Res 2013, 471:2776-2782.

17. Bellabarba C, Berger RA, Bentley CD, et al: Cementless acetabular reconstruction after acetabular fracture. J Bone Joint Surg Am 2001, 83A:868-876.

18. Giannoudis PV, Grotz MR, Papakostidis C, Dinopoulos H: Operative treatment of displaced fractures of the acetabulum. A meta-analysis. J Bone Joint Surg Br 2005, 87:2-9.

19. Mears DC, Velyvis JH: Primary total hip arthroplasty after acetabular fracture. Instr Course Lect 2001, 50:335-354. 
20. Sen RK, Tripathy SK, Aggarwal S, Tamuk T: Posterior wall reconstruction using iliac crest strut graft in severely comminuted posterior acetabular wall fracture. Int Orthop 2011, 35:1223-1228.

21. Daum WJ: Traumatic posterior acetabular defects reconstructed with iliac crest autograft. A report of two cases. Clin Orthop Relat Res 1993, 291:188-192.

22. Zha GC, Sun JY, Chen $L$, et al: Late reconstruction of posterior acetabular wall fractures using iliac crest. J Trauma 2012, 72:1386-1392.

doi:10.1186/1471-2474-14-368

Cite this article as: Zhang et al: Massive heterotopic ossification associated with late deficits in posterior wall of acetabulum after failed acetabular fracture operation. BMC Musculoskeletal Disorders 2013 14:368.

\section{Submit your next manuscript to BioMed Central and take full advantage of:}

- Convenient online submission

- Thorough peer review

- No space constraints or color figure charges

- Immediate publication on acceptance

- Inclusion in PubMed, CAS, Scopus and Google Scholar

- Research which is freely available for redistribution 